\title{
Tensioactivos e polímeros solúveis em água - de um entendimento molecular a aplicações técnicas
}

\author{
MARIA DA GRAÇA MIGUEL *
}

\section{INTRODUÇÃO}

As misturas polímero-tensioactivo são ubíquas em tecnologia e desempenham um papel de extrema importância nos sistemas biológicos. O controlo das interacções entre macromoléculas e compostos anfifílicos é a chave de variadíssimas formulações e de funções biológicas essenciais. A extensa gama de aplicações baseia-se fundamentalmente na sua adsorção a diferentes superfícies, de que são exemplo os processos de limpeza e a estabilização de dispersões, e nas suas propriedades de solução, como os aspectos de auto-agregação. Polímeros e tensioactivos são utilizados muitas vezes em conjunto para atingir, por exemplo, estabilidade coloidal e controlo reológico [1-3]. Neste artigo será dada uma breve visão das interacções polímero-tensioactivo e seleccionadas algumas das aplicações nesta área. No sentido de chamar a atenção para um assunto de crucial importância actual, inicia-se com alguns exemplos sobre a aplicação destes sistemas a questões energéticas, após o que serão considerados aspectos básicos gerais destes sistemas. Far-se-à depois referência ao desenvolvimento de novos sistemas-gel, bem como a potenciais aplicações na formulação de fármacos.

\section{INTERACÇÕES \\ POLÍMERO-TENSIOACTIVO E TECNOLOGIA}

Durante as últimas décadas a química de colóides e superfícies tem atraído vastos interesses ligados ao problema da energia. Em muitos casos é significativo o papel conjugado de compostos anfifílicos, como tensioactivos e polímeros solúveis em água [4-9]. Mencionamos três situações em que princípios simples levaram a desenvolvimentos importantes e à motivação da investigação fundamental, a qual contribuiu consideravelmente para a compreensão dos processos de adsorção e auto-agregação de polímeros e tensioactivos.
A primeira situação a considerar é o desenvolvimento de suspensões carvão-água, como substituintes do petróleo como combustível. Nas suspensões carvão-água [4], dispersa-se carvão finamente dividido em água, a um nível de ca. $70-75 \%$. Sem aditivos, observar-se-ia rapidamente a separação por sedimentação ou uma viscosidade tão elevada que tornaria difícil o bombeamento e a atomização. Os aditivos têm como papel introduzir forças repulsivas, reduzir a fricção entre partículas, e criar uma rede molecular "solta" que retarda a velocidade de sedimentação.

Diferentes grupos de investigadores têm utilizado de alguma forma diferentes princípios no desenvolvimento das suspensões carvão-água. Um exemplo de formulação consiste num sistema baseado essencialmente em três compostos químicos [5]. Um dos aditivos é a lecitina, um lípido zwiteriónico, que adsorve fortemente à superfície do carvão e cria uma forte interacção repulsiva de curta distância entre partículas (interacção muitas vezes referida como "força de hidratação", contudo este termo pode ser enganoso). Um outro, um copolímero de bloco, hidrofílico-hidrofóbico, do tipo poli(óxido de etileno)-poli(óxido de propileno), que adsorve fracamente à superfície das partículas e origina uma interacção repulsiva a maiores distâncias, a que se chama estabilização esterea. O terceiro aditivo, um polissacarídeo de elevado peso molecular, como o xantato de celulose, origina uma rede molecular.

O segundo caso respeita ao desenvolvimento de técnicas de desidratação da turfa, um recurso potencial de energia em muitos países. A turfa pode ser, após desidratação, uma fonte de energia importante [6], contudo, o problema principal é o elevado teor de água, superior a $90 \%$, e a dificuldade de desidratação. Vários estudos mostraram que o problema não reside na "ligação" da água, mas num efeito coloidal, e de superfície, na permeabilidade da água [7]. Assim, pressionando a água para fora da turfa, partículas pequenas, frequentemente de tamanho coloidal, obstroem os poros e impedem efectivamente o transporte de água. Estas partículas, dada a sua carga negativa, são estabilizadas electrostaticamente, mas através de floculação a água pode ser muito mais facilmente removida. Como consequência, foi desenvolvida uma técnica na qual são adicionadas pequenas quantidades de um tensioactivo catiónico, de um polielectrólito catiónico, ou a combinação destes. A Figura 1 mostra como, com a poli-imina, o tempo necessário para obter o conteúdo de água ao nível desejado pode baixar significativamente.

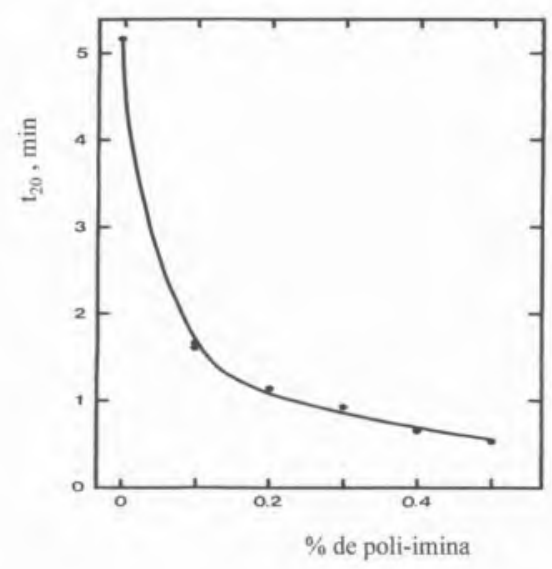

Fig. 1, Devido a interacçōes coloidais, a adição de um polímero ou tensioactivo de carga positiva à turfa (carga negativa) facilita a desidratação. A figura mostra o tempo necessário para que, sob pressão, se atinja um contéudo sólido de $20 \%$. (Adaptada da Ref. 7.)

Finalmente, o terceiro caso diz respeito ao desenvolvimento de técnicas de recuperação de petróleo, recorrendo a microemulsões e outras soluções de tensioactivos. Com técnicas convencionais cerca de $60-70 \%$ de petróleo fica nos poços, principalmente devido à sua localização em poros muito estreitos. Inúmeros esforços têm sido feitos para reduzir esta percentagem e diferentes técnicas sugeridas e ensaiadas em experiências de laboratório e de campo. Uma das mais comuns baseia-se no bombeamento de uma solução de tensioactivo e/ou polímero nos poços 
[8]. As soluções de tensioactivo podem alterar as tensões interfaciais e reduzir a área de contacto entre as gotas de óleo e os poros da pedra, facilitar o desprendimento e, portanto. o transporte de petróleo.

Para o movimento do petróleo através dos poros estreitos são desejáveis tensões interfaciais óleo/água muito baixas, ca. $10^{-6} \mathrm{~N} / \mathrm{m}$. Tais condições podem ser atingidas em sistemas de tensioactivo-hidrocarbonetoágua chamados microemulsões, que são soluções isotrópicas de três componentes, homogéneas, de uma simples fase. Por escolha apropriada do tensioactivo, ou mistura de tensioactivos, uma pequena quantidade, ca. $1 \%$, é suficiente para misturar iguais volumes de água e hidrocarboneto. Os dois solventes são segregados localmente, com o tensioactivo a formar um filme divisório monomolecular $[9,10]$. Contudo, mesmo o uso de tão baixa quantidade de tensioactivo não é rentável em termos económicos, dado os actuais preços do petróleo. O facto de um polímero adicionado em pequenas quantidades a uma solução de tensioactivo poder, sob certas condições, baixar de uma forma significativa a tensão interfacial óleo-água, tem suscitado um enorme interesse nos sistemas polímero- tensioactivo nesta área.

\section{ASPECTOS BÁSICOS DAS INTERACÇÕES POLÍMERO-TENSIOACTIVO}

Os exemplos anteriores, dirigidos a um problema específico, servem para ilustrar a importância das interacções polímero-tensioactivo. Goddard discutiu genericamente algumas aplicações e identificou diferentes mecanismos [1]. Mostrou, em particular, que as aplicações se baseiam em diversos factores como a depressão do ponto de turvação de uma solução de polímero, solubilização, aumento de viscosidade, diminuição da concentração do monómero de um tensioactivo, modificação das propriedades de adsorção e capacidade de formação de espuma.
Uma descrição muito útil dos sistemas polímero-tensioactivo é feita em termos de auto-agregação do tensioactivo no polímero, ou da auto-agregação do tensioactivo induzida pela presença do polímero. Nesta perspectiva, os princípios de auto-agregação de tensioactivos, em geral bem estabelecidos, podem ser utilizados para prever características importantes dos sistemas polímerotensioactivo. Os tensioactivos são compostos anfifílicos, que ao combinar as propriedades de solutos polares com as de hidrocarbonetos apresentam porções hidrofílicas e lipofílicas muitas vezes bem segregadas. Isto leva a uma ambivalência em sistemas aquosos, e por sua vez a adsorção a interfaces - água/ar, água/hidrocarboneto, água/sólido, água/macromolécula ou a auto-agregação, isoladamente ou com co-solutos de maior ou menor massa molecular.

A auto-agregação é uma forma eficiente de eliminar o contacto relativamente desfavorável, sob o ponto de vista energético, entre a parte lipofílica e o meio aquoso, mantendo um contacto com a água para os grupos polares. Este fenómeno conduz à formação de agregados micelares, tipicamente esféricos a baixa concentração, mas em muitos casos cilíndricos a concentração mais elevada. Estas soluções micelares, que não apresentam ordem a longa distância, são apenas um exemplo de agregados de tensioactivo caracterizados por um polimorfismo extremamente rico.

No que respeita a sistemas diluídos, as isotérmicas de ligação oferecem uma descrição alternativa, existindo vários estudos que elucidam as características de ligação de um tensioactivo a um polímero, e demonstram que o processo de ligação é cooperativo e começa a uma concentração de agregaçâo crítica, cac (Fig. 2). Neste e noutros aspectos importantes, a dependência da concentração de várias propriedades físico-químicas é idêntica à da auto-agregação de tensioactivos em micelas; por exemplo, a cac varia qualitativamen-

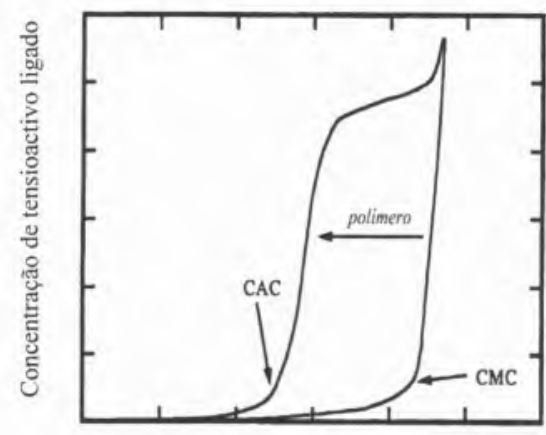

Concentração de tensioactivo livre

Fig. 2. A isotérmica de ligação de um tensioactivio a um polímero sem unidades hidrofóbicas distintas, pode ser interpretada como o abaixamento de cmc do tensioactivo pelo polímero, ou como um processo fortemente cooperativo. (Adaptada da Ref. 11.)

te do mesmo modo que a concentração micelar crítica $(\mathrm{cmc})$ com o comprimento da cadeia alquílica do tensioactivo [2]. Isto sugere que, como alternativa a interpretar a associação em termos de ligação do tensioactivo ao polímero, pode ser mais apropriado considerar o efeito do polímero na micelização do tensioactivo. Um polímero não-iónico faria baixar a cmc como resultado da presença de segmentos anfifílicos e lipofílicos, enquanto que no caso de um polielectrólito, a interacção seria explicada por efeitos electrostáticos. Tensioactivos não-iónicos não se ligam em geral a polímeros; este facto pode estar relacionado com a alta estabilidade das micelas não-iónicas (baixa $\mathrm{cmc}$ ), o que implica pouco ou nenhum ganho em energia na formação de micelas na presença das cadeia de polímero.

Independentemente do modo como se considera a interacção, a descrição que emerge do estudo termodinâmico dos sistemas diluídos é a de agregados do tipo micelar de moléculas de tensioactivo ao longo da cadeia do polímero [11]. A proximidade do contacto micela-polímero variará consideravelmente com a natureza dos sistemas, de um contacto mais "apertado" em polímeros que contêm segmentos hidrofóbicos, para um contacto mais "solto" em certos sistemas polielectrólito-tensioactivo 
iónico. Estudos de dispersão de neutrões, ressonância magnética nuclear e de supressão de fluorescência apoiam a descrição geral de uma estrutura do tipo "colar de pérolas" [12] (Fig. 3).

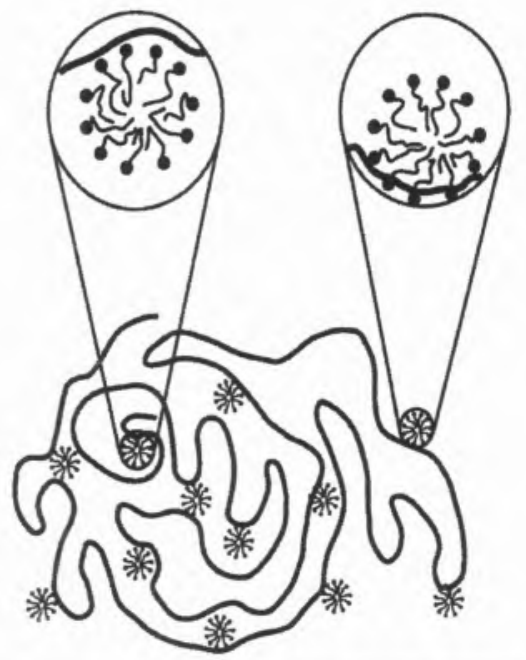

Fig. 3. Modelo de "colar de pérolas" para uma associação tensioactivo-polimero. (Adaptada da Ref. 2.)

Se considerarmos a formação de estruturas e propriedades reológicas, parece natural uma discussão em termos de ligação de tensioactivo ao polímero e o efeito desta nas interacções intra- e intercadeias. $\mathrm{O}$ efeito dependerá da relação entre a concentração efectiva de polímero e a concentração onde começa a sobreposição das cadeias, $\mathrm{c}^{*}$. No caso de um tensioactivo iónico, quando ligado a um polímero não-iónico, espera-se que cause expansão do polímero, e contracção no caso de um polielectrólito de carga oposta. Isto conduz a um aumento e a um decréscimo de viscosidade, respectivamente, em soluções diluídas. Para soluções semi-diluídas ou concentradas, o efeito é mais complexo; a ligação do tensioactivo pode aumentar ou baixar $c^{\star}$. Um mecanismo de grande interesse é, para concentrações acima de $c^{*}$, a possibilidade de uma micela interaccionar com mais do que uma cadeia de polímero (Fig. 4). Este tipo de reticulação tem obviamente um enorme efeito nas propriedades reológicas destes sistemas.

\section{FORMAÇÃO DE GEL NUM SISTEMA DE UM POLÍMERO NÃO-IÓNICO E UM TENSIOACTIVO IÓNICO}

Para muitos polímeros não-iónicos usados em várias aplicações, como éteres de celulose e copolímeros de bloco, óxido de etileno-óxido de propileno, o ponto de turvação é

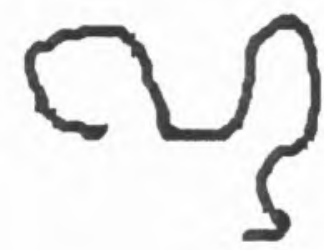

+ tensioactivo
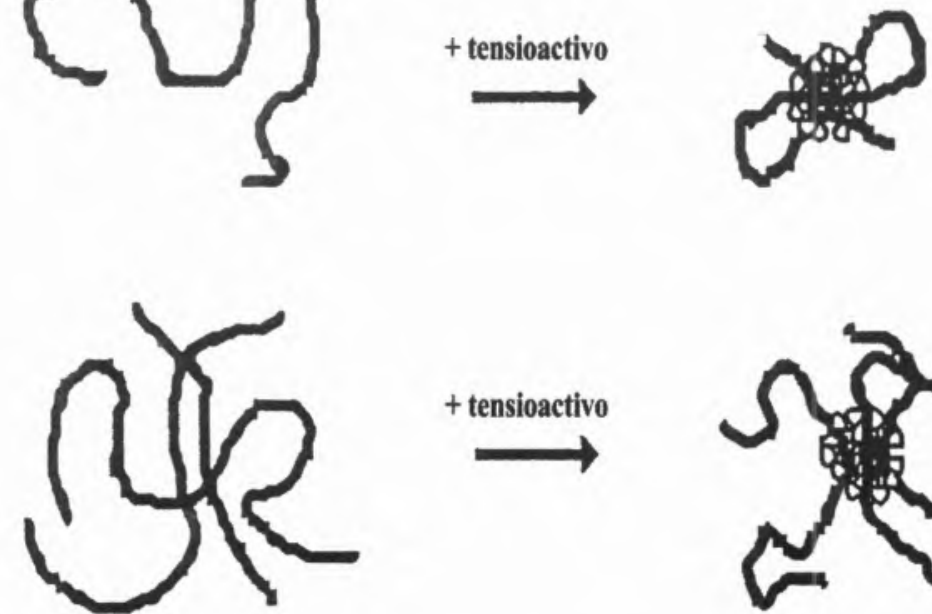

+ tensioactivo

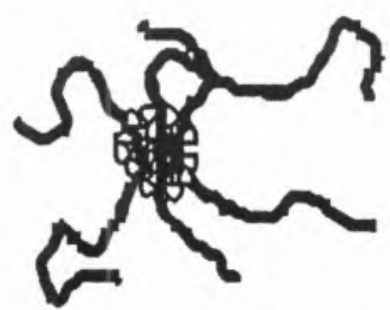

Fig. 4. Visualização da reticulação de cadeias de polímero por micelas de tensioactivo para soluções de polímero diluídas e semi-diluídas ou concentradas, respectivamente. um fenómeno muito importante que depende, mais ou menos significativamente, da presença de diferentes co-solutos [13]. Em particular, a adição de tensioactivos iónicos causa um aumento drástico do ponto de turvação, mesmo a baixa concentração.

Os polímeros não-iónicos interaccionam normalmente com tensioactivos iónicos $[1,11,12]$. Estes sistemas mistos têm sido considerados muito relevantes na produção de novas estruturas e formulações com novas propriedades reológicas, uma vez que os efeitos físicos de reticulação podem ser modelados pelo tensioactivo iónico e pela temperatura. Como estes polímeros se tornam menos polares a temperaturas mais elevadas [13] oferecem melhores núcleos para a auto-agregação de tensioactivo a uma maior temperatura; num regime de semi-diluição poderá ser mesmo possível a reticulação de cadeias do polímero por micelas de tensioactivo.

Os éteres de celulose não-iónicos, como etil-hidroxietil de celulose (EHEC), constituem um exemplo interessante. O grau de substituição dos grupos etilo e hidroxietilo pode variar, o que permite obter um polímero com um ponto de turvação desejado; a estrutura na Figura 5 representa uma substituição comum que conduz a um ponto de turvação ca. $70{ }^{\circ} \mathrm{C}$. Uma solução aquosa de EHEC ca. $1 \%$ mostra um aumento moderado de viscosidade comparativamente à água; efeito este que diminui com a temperatura. Na presença de uma pequena quantidade de tensioactivo $(0.1-0.5 \%)$, a viscosidade é relativamente baixa e as soluções são normalmente fluidas a baixa temperatura. Contudo, aumentando a temperatura observa-se um enorme aumento de viscosidade, como se ilustra na Figura 6. A baixa temperatura, as soluções apresentam uma viscosidade baixa e as propriedades reológicas são dominadas por efeitos de viscosidade, enquanto a temperatura mais elevada a viscosidade aumenta significativamente e os efeitos elásticos tornam-se dominantes [14]. O 


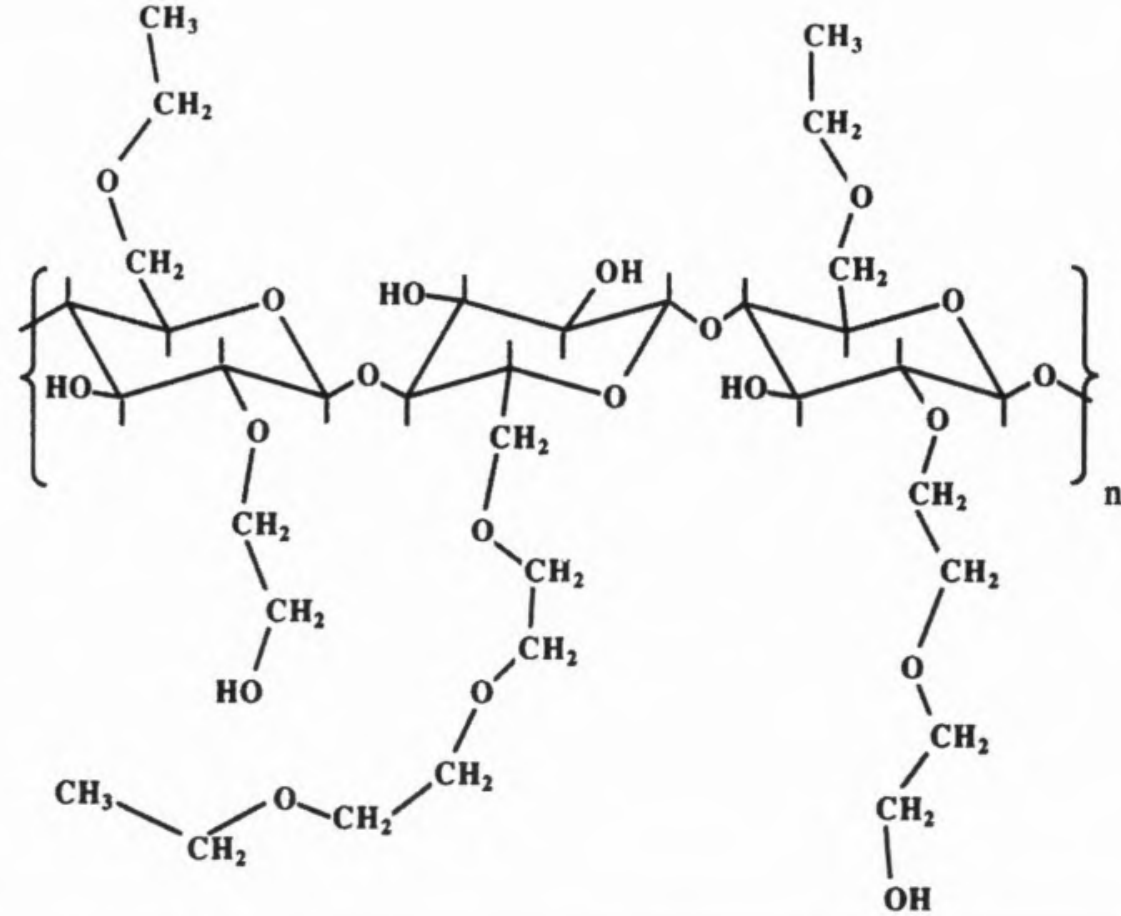

Fig. 5. Estrutura molecular de um segmento de etil-hidroxietil de celulose (EHEC).

sistema pode assim ser caracterizado como variando de uma solução viscosa para um gel, com o aumento da temperatura; o processo é reversível e o gel "funde" por arrefecimento. O mecanismo molecular é aparentemente o de uma reticulação combinada com auto-agregação de tensioactivo, sendo este processo facilitado a temperatura elevada, onde o polí-

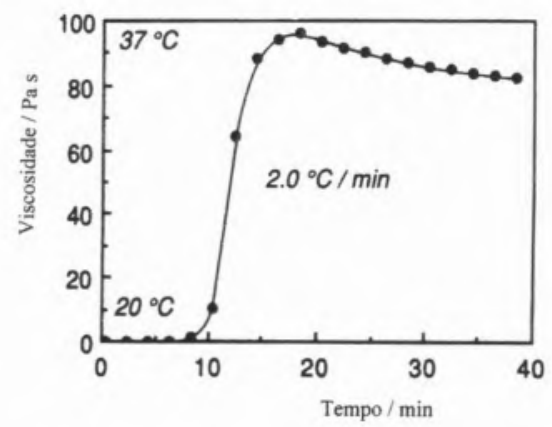

Fig. 6. Um aumento da temperatura, de $20^{\circ} \mathrm{C}$ para $37^{\circ} \mathrm{C}$, de uma solução de um polímero nẫo-iónico (EHEC, 1\%) e de um tensioactivo iónico, dodecilsulfato de sódio (SDS, $3 \mathrm{mM}$ ), leva a um aumento significativo de viscosidade $\mathrm{e}$ à formação de gel. (Adaptada da Ref. 15.) mero é mais hidrofóbico. A temperatura à qual se dá a formação deste gel está relacionada com o ponto de turvação do sistema polímero-água e pode ser escolhida de acordo com o grau de substituição.

\section{FORMAÇÃO DE GEL INDUZIDA POR TEMPERATURA E APLICAÇÕES FARMACÊUTICAS}

Como farmacologicamente activos - fármacos solúveis em água podem ser geralmente dissolvidos em sistemas polímero-tensioactivo estes sistemas, que apresentam uma baixa viscosidade à temperatura ambiente mas formam espontaneamente um gel à temperatura do corpo humano, oferecem um novo impacto na administração e transporte controlado de fármacos $[15,16]$. O processo de gelificação é independente da presença de outras espécies no meio e requer concentrações muito baixas de polímero e tensioactivo $(<1 \%)$. Além disso, o sistema é compatível com diferentes modos de administração e apresenta uma longa estabilidade. Outros sistemas aquosos de polímero conhecidos por gelificar in situ requerem concentração elevada de sal, baixo $\mathrm{pH}$ ou concentração elevada de polímero.

O tipo de EHEC usado nestas aplicações tem um ponto de turvação na zona de $30-35^{\circ} \mathrm{C}$. Este polímero forma um gel após subida de temperatura, quando presente um tensioactivo iónico em concentração apropriada; no caso do dodecilsulfato de sódio (SDS) é 0.05-0.15\%. A mistura EHEC-tensioactivo iónico que forma um gel em sucos gástrico e intestinal simulados, retardando assim a libertação de substâncias activas, é um líquido bebível à temperatura ambiente.

\section{SISTEMAS POLIELECTRÓLITO- -TENSIOACTIVO}

Enquanto nos sistemas de polímeros não-iónicos a interacção polímero-tensioactivo é modelada pela temperatura, em sistemas de polímeros iónicos espera-se que a concentração de electrólito seja o factor decisivo nas interacções. De facto, observa-se normalmente que um polielectrólito e um tensioactivo de carga oposta se agregam para formar um gel que se dissolve por adição de um electrólito [17].

Uma forma muito útil de caracterizar estes sistemas é através de diagramas de fase. A Figura 7 mostra o comportamento típico de um sistema constituído por um tensioactivo iónico, um polielectrólito e água, para diferentes concentrações do electrólito. Na ausência de electrólito há uma forte agregação do polímero e do tensioactivo, com a formação de uma fase gel em equilíbrio com uma solução muito diluída. A adição de electrólito faz diminuir as atracções electrostáticas levando à dissolução do gel e à eliminação da separação de fase. Contudo, para concentrações de electrólito suficientemente elevadas, observa-se novamente uma separação em duas fases. Esta separação de fase é todavia de uma nature- 

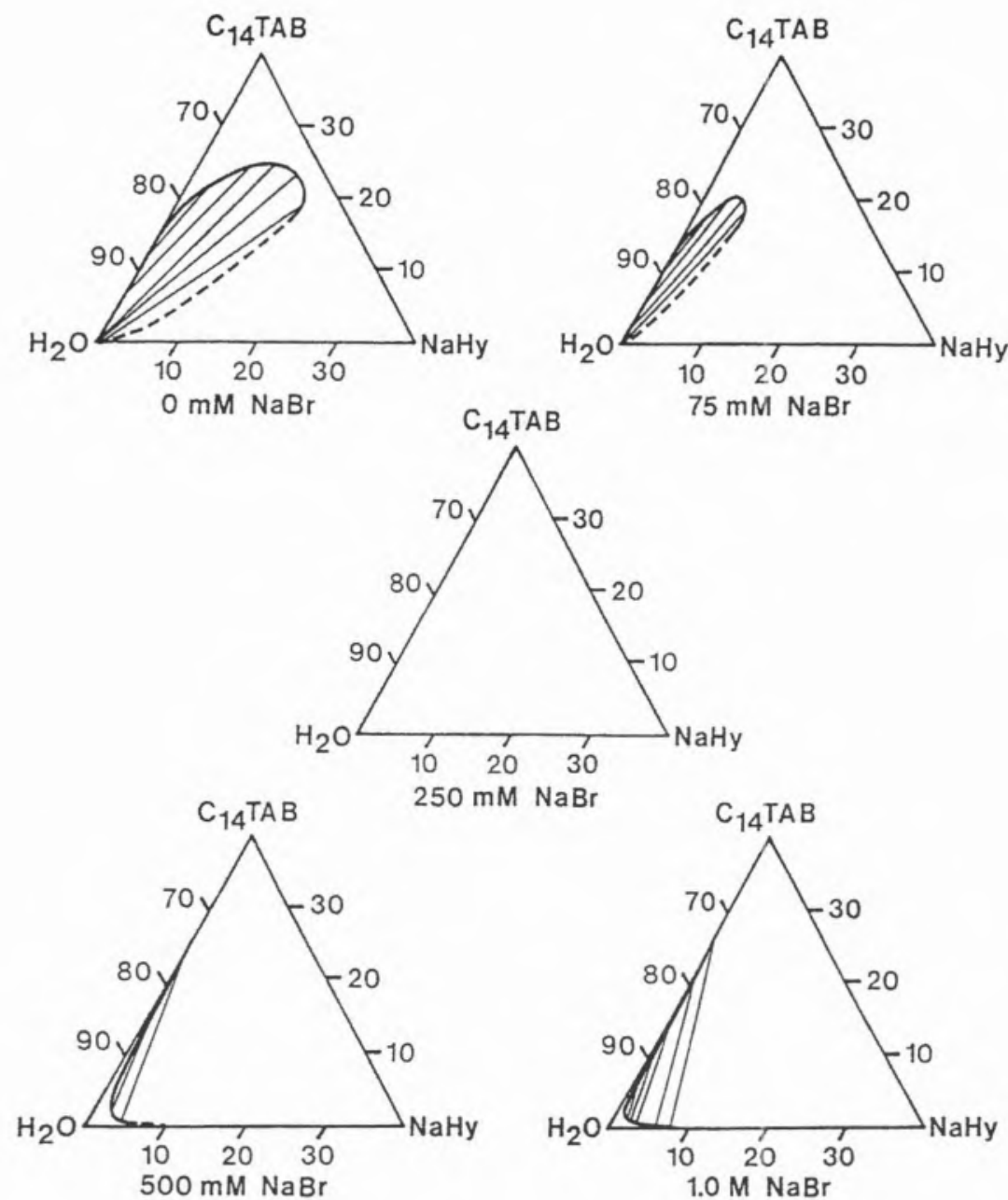

$\mathrm{C}_{14} \mathrm{TAB}$

$75 \mathrm{mM} \mathrm{NaBr}$
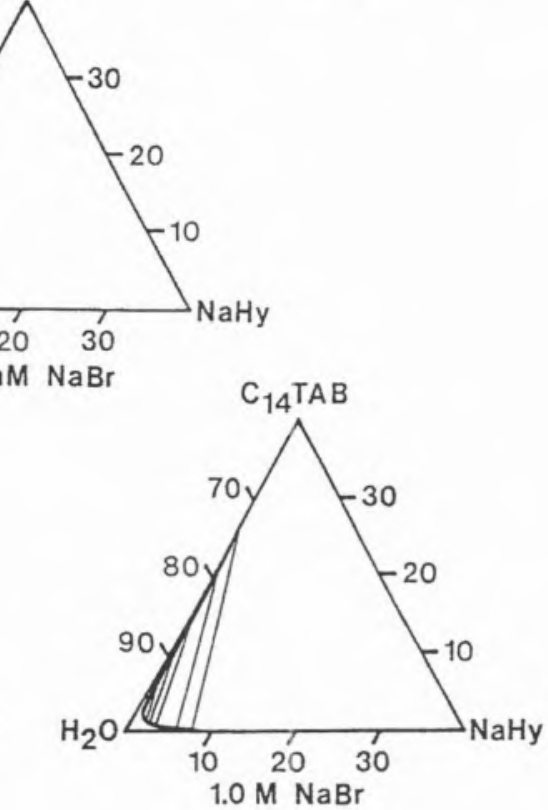

Fig. 7. Diagrama de fase pseudo-ternário para um sistema de um polissacarídeo aniónico, hialuronato de sódio, $\mathrm{NaHy}$, e um tensioactivo catiónico, brometo de tetradeciltrimetilamónio, $\mathrm{C}_{14} \mathrm{TAB}$, a diferentes concentrações de sal, NaBr. (Adaptada da Ref. 17.)

za diferente da descrita anteriormente, e resulta em duas fases constituídas por soluções de baixa viscosidade, uma rica em polímero e outra rica em tensioactivo. Consequentemente, com o aumento da concentração do electrólito o sistema passa de uma natureza associativa para segregativa. As implicações deste comportamento de fase em processos de purificação e separação são óbvias.

Para sistemas de tensioactivos e polímeros de carga semelhante os diagramas de fase mostram um comportamento segregativo na ausência e na presença de electrólito.

\section{DESENVOLVIMENTO E PERSPECTIVAS}

Este artigo dá apenas uma breve referência a tópicos seleccionados num campo de grande actualidade. Os sistemas mistos de polímeros e tensioactivos ocorrem em numerosos produtos e processos, além disso a interacção entre moléculas anfifílicas e macromoléculas é a base de muitos mecanismos e funções biológicas. Os esforços de investigação têm-se dirigido para sistemas em solução diluída, para os quais já existe um bom entendimento da maior parte dos as- pectos básicos. Sabe-se, por estudos de supressão de fluorescência e de NMR que, na presença de polímero, se formam agregados de tensioactivo idênticos a micelas normais. O contacto entre polímero e agregados de tensioactivo pode ser mais ou menos próximo, dependendo da natureza do polímero. O primeiro caso encontra-se nos polímeros modificados hidrofobicamente e os agregados podem ser caracterizados como micelas mistas [18]. Em polielectrólitos típicos há um contacto menos próximo e os solutos interaccionam principalmente via interacção electrostática de longa distância. A determinação sistemática de números de agregação para diferentes tipos de sistemas de tensioactivos é de extrema importância na extensão dos conhecimentos neste campo [19].

Estudos sistemáticos em sistemas concentrados são menos frequentes, embora possam ser considerados da maior relevância no que respeita a aplicações. A reticulação de cadeias de polímero por micelas de tensioactivo é, portanto, um aspecto importante, pelo que estudos estruturais de sistemas reticulados, em particular novos sistemas gel, contribuem efectivamente para o desenvolvimento de produtos em diversas áreas, como na administração de fármacos e formulações de tintas. Um outro aspecto interessante é o estudo de diagramas de fase que são normalmente ricos em informação sobre as interacções nestes sistemas [3]

Para o progresso conceptual neste campo é importante sublinhar a analogia entre os sistemas polímero-tensioactivo-água e os sistemas de dois polímeros-água, bem como o uso dos conhecimentos já estabelecidos sobre a auto-agregação de tensioactivos [20]. Igualmente relevante é o desenvolvimento de estudos em condições nas quais o tensioactivo pode formar agregados mais extensos do que as micelas esféricas "mínimas", em particular o estudo da compatibilidade entre diferentes fases líquido-cristalinas, mormente fases lamelares, e polímeros de diferentes tipos [21]. 
Os sistemas mistos de tensioactivos catiónicos e aniónicos, referidos como cataniónicos [22], oferecem excelentes possibilidades no controlo da densidade de carga e estrutura dos agregados, levando, por exemplo, à formação de vesículos termodinamicamente estáveis $[23,24]$. Sistemas de vesículos cataniónicos e polielectrólitos, com e sem modificação hidrofóbica, mostram uma certa analogia com sistemas polímero-micela [25]; é ainda de extrema relevância o desenvolvimento de estudos da interacção destes agregados com DNA [26].

\section{AGRADECIMENTOS}

A autora agradece aos Professores $\mathrm{H}$. Burrows e B. Lindman os valiosos comentários ao manuscrito. Agradece também à Fundação para a Ciência e a Tecnologia a concessão de uma bolsa no âmbito do Programa FMRH, e o apoio através do projecto Praxis XXI( 2/2.1/QUI/411/94), que lhe permitiram desenvolver trabalho de investigação nesta área.

\footnotetext{
* Departamento de Química

Universidade de Coimbra, 3049 Coimbra

(e-mail:mgmiguel@ci.uc.pt)
}

\section{REFERÊNCIAS}

1. E.D. Goddard, K.P. Ananthapadmanabhan (eds), Interactions of Surfactants with Polymers and Proteins, CRC Press, Boca Raton, Florida, 1993.

2. B. Jönsson, B. Lindman, K. Holmberg, B. Kronberg, Surfactants and Polymers in Aqueous Solution, John Wiley \& Sons, New York, 1998.

3. L. Piculell, B. Lindman, G. Karlstörm, Phase behavior of polymer/surfactant systems, in PolymerSurfactant Systems, J.C.T. Kwak (ed), Marcel Dekker, New York, 1998

4. T. Tadros, Inst. Chem. Eng. Symp. Ser., 1985, p. 1.

5. L. Stigson, B. Lindman, PCT Int. Appl. WO 8300 (1983) 500, SE Appl. 8114 (1981) 645; Proc. Engineering, April 1985, p. 11; L. Stigson, Aufbereit Tech. 26 (1985) 513; A. Bergh, Kem. Tidskr. 7 (1983) 10.

6. Proc. 6th Int. Peat Congress, Duluth, MN, 1980
7. B. Jönsson, E. Petersson, B. Lindman, Fuel, 66 (1987) 785 .

8. D.O. Shah, R.S. Schechter, Improved oil recovery by surfactant and polymer flooding, Academic Press, New York, 1977.

9. K. Shinoda, B. Lindman, Langmuir, 3 (1987) 135

10. A. Kabalnov, B. Lindman, U. Olsson, L. Picullel, K. Thuresson, H.Wennerström, Colloid Polym. Sci., 274 (1996) 297

11. B. Lindman, K. Thalberg, Polymer-surfactant interactions - recent developments, in Interactions of Surfactants with Polymers and Proteins, E.D. Goddard, K.P. Ananthapadmanabhan (eds), CRC Press, Boca Raton, Florida, 1993, p. 203.

12. B. Cabane, J. Phys. Chem. 81 (1977) 1639; B. Cabane, R. Duplessix, J. Physique 43 (1982) 1529.

13. B. Lindman, A. Carlsson, G. Karlström, M. Malmsten, Adv. Colloid Interface Sci., 32 (1990) 183.

14. A. Carlsson, G. Karlström, B. Lindman, Colloids Surf., 47 (1990) 147.

15. B. Lindman, A. Carlsson, K. Thalberg, C. Bogentoft, L'áctualitée chimique, 1991, p. 187.

16. K. Thalberg, B. Lindman, Langmuir, 7 (1991) 277.
17. K. Thalberg, B. Lindman, G. Karlström, J. Phys. Chem., 95 (1991) 6004

18. I. Iliopoulos, T.K. Wang, R. Audebert, Langmuir, 7 (1991) 617 .

19. P.P Infelta, M. Grätzel, J.K. Thomas, J. Phys. Chem. 78 (1974) 190; M. Tachiya, Chem. Phys. Lett, 33 (1975) 289; M. Almgren, J.-E. Löfroth, J. van Stam, J. Phys. Chem. 90 (1986) 4431.

20. L. Piculell, B. Lindman, Adv. Colloid Interface Sci., 41 (1992) 149.

21. P.G. de Gennes, J. Phys. Chem., 94 (1990) 8407 .

22. A. Khan, E. Marques, Catanionic Surfactants, in Specialists Surfactants, I. D. Rob (ed); Blackie Academic and Professional, Chapman \& Hall, London, 1997, p. 37.

23. E.W. Kaler, A.K. Murthy, B.E. Rodriguez, J.A. Zasadzinski, Science, 245 (1989) 1371.

24. E. Marques; A. Khan, M.G. Miguel, B. Lindman, I. Phys. Chem., 97 (1993) 4729.

25. E. Marques, O. Regev, A. Khan, M.G. Miguel, Langmuir, 15 (1999) 642.

26. M.G. Miguel, E. Marques, R. Dias, S.M. Mel'nikov, A. Khan, B. Lindman, Colloids and Surfaces, 112 (1999) 157.

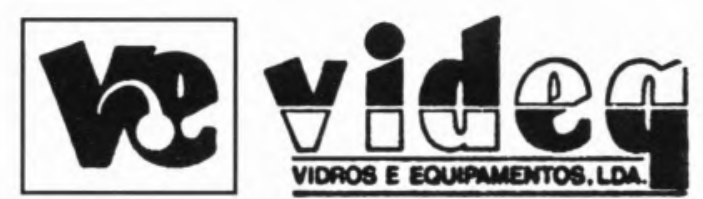

Equipamento de Laboratório

Balanças - Centrifugas - Aparelhos de $\mathrm{pH}$ - Tituladores Condutímetros - Agitadores - Espectrofotómetros Microscópios - etc.

Vidros e Plásticos de Laboratório Distribuidores NORMAX

\section{Material Didáctico}

Ensino Secundário e Superior

Representantes exclusivos SISTEDUC - Sistemas Educativos S.A.

Rua Soeiro Pereira Gomes, 15 r/c Frente

Bom Sucesso - 2615 Alverca

Telefs. (01) 95704 20/1/2 - Fax (351-1-957 04 23) - Portugal 